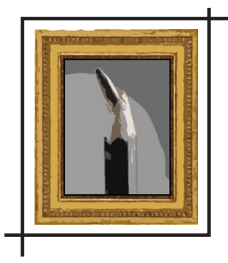

\title{
AVALIAÇÃO DE PRÁTICAS PARENTAIS EM MÃES ENCARCERADAS*
}

\author{
Gabriela Reyes Ormeno** \\ Juliana Saito*** \\ Jose C. Fogo****
}

Resumo: Pouco se estuda sobre a população carcerária brasileira e muito menos sobre seus familiares. Essa população, crescente a cada dia, torna-se invisivel aos olhos da sociedade, pois trata-se de pessoas estigmatizadas e rotuladas como "más". No entanto, a influência dela é mais marcante do que se aparenta. Afinal, não só a população carcerária tem peso para a economia do pais, como também seus familiares, principalmente os filhos que correm sérios riscos de tornarem-se a próxima geração de encarcerados, construindo assim um ciclo da violência que dificilmente se rompe. 0 presente estudo teve por objetivo avaliar práticas parentais utilizadas por mães que se encontram encarceradas. Para tal, foi aplicado o Inventário de Estilos Parentais (IEP) em mulheres encarceradas, com o intuito de obter informações sobre a transmissão intergeracional dos estilos parentais. Analisaram-se duas gerações, primeiramente entendendo quais práticas parentais foram utilizadas com a mulher encarcerada quando criança e, depois, quais práticas educativas ela adotou com o filho antes do encarceramento, contribuindo assim para entendermos a intergeracionalidade da violência. Os resultados mostraram que a prática educativa mais utilizada pela mulher encarcerada e por sua mãe foi a monitoria negativa, o que pode sugerir uma transmissão intergeracional de tal prática.

Palavras-chave: Estilos parentais. Mulheres encarceradas. Fatores de risco. Intergeracionalidade. Avaliacão.

\section{AVALIAÇÃO DE PRÁTICAS PARENTAIS EM MÃES}

A violência se apresenta como fenômeno notável e pode-se pensar na população carcerária como reflexo direto desse processo. As mulheres encarceradas representam apenas 7\%

\footnotetext{
* Agradecemos ao Conselho Nacional de Desenvolvimento Científico e Tecnológico (CNPq) o fomento financeiro - Processo n. 402958/2008-0 - e a bolsa de iniciação científica para a segunda autora. Agradecemos ainda à Coordenação de Aperfeiçoamento de Pessoal de Nivel Superior (Capes) a bolsa de doutorado da primeira autora.

** Departamento de Educação, Universidade Federal do Paraná.E-mail: gabrielareyes@ufpr.br

*** Psicóloga. E-mail: jusaito10@gmail.com

**** Departamento de Estatística da Universidade Federal de São Carlos. E-mail: fogo@ufscar.br
} 
da população carcerária do Brasil, e, em 2018, o último relatório do Departamento de Assistência Penitenciaria (Depen) apontava um total de 726 mil. No entanto, a mulher encarcerada brasileira representa a quarta população no ranking mundial com $42.355^{1}$ das mais 714 mil mulheres encarceradas no mundo. Essa mulher pode ser caracterizada como sendo: jovem, afrodescendente, chefe de familia monoparental, geralmente condenada pelo envolvimento com o tráfico de drogas e mãe de pelo menos uma criança (SCHERER; SCHERER, 2009; CANAZARO; ARGIMON, 2010; ORMENO; MAIA; WILLIAMS, 2013).

Nos Estados Unidos, a população carcerária vem sendo estudada há muitos anos, sendo possivel encontrar material referente desde 1910. Destacam-se aqui os seguintes trabalhos: Dalley (2002) analisou a vida das encarceradas pós-encarceramento, Ferraro e Moe (2003) estudaram a relação entre maternidade, crime e encarceramento, Laughlin et al. (2008) investigaram a questão da visita dos filhos às penitenciárias, e Lee, Fang e Luo (2013) apontaram os impactos no desenvolvimento físico das crianças. De acordo com Lee, Fang e Luo (2013), a maioria das ex-presidiárias volta a viver com os filhos, mas não consegue manter-se não usuária de drogas ou refrear o ato de cometer crimes, entre outros aspectos.

Em âmbito nacional, Stella (2009) considerou o papel materno na socialização dos filhos de encarceradas e verificou que os valores culturais básicos das crianças se sedimentam não apenas pela presença da mãe, mas também pela fala e pelo apoio dos outros significativos - por exemplo, a figura da avó. Essa questão é muito pertinente, pois, como apontado por Ormeno, Maia e Williams (2013), após o encarceramento da mãe, são os avós que ficam com a guarda das crianças. Outras pesquisas visam descrever como a mulher encarcerada exerce a sua maternidade, como se dá a relação de mães e filhos que convivem em ambiente prisional e ainda quais são os padrões de apego entre mães e filhos no cárcere (COSTA; VIEIRA; PESSINI, 2011).

Mesmo antes de a mãe ter sido presa, o ambiente em que a criança estava inserida pode ter sido fonte de diversos fatores de risco ao seu desenvolvimento, como exposição à violência conjugal paterna, uso de droga por parte dos pais ou por pessoas que convivem no mesmo ambiente, e também pelo uso de práticas educativas negativas por parte da própria mãe (DALLEY, 2002). Dessa maneira, Soares e Ilgenfritz (2002) confirmaram a hipótese de que a cadeia é apenas mais um elo de múltiplas violências que conformam a trajetória de uma parte da população feminina. 0 ciclo da violência, que se inicia na família e nas instituições para crianças e adolescentes, perpetua-se no casamento, desdobra-se na ação tradicional das polícias e se completa na penitenciária para recomeçar, provavelmente, na vida das futuras egressas, sem esquecer-se dos filhos que correm sérios riscos de tornarem-se a próxima geração de encarcerados por estarem expostos aos mesmos fatores de risco da geração materna.

1 - Esses dados são flutuantes por causa da rotatividade do sistema penitenciário. 


\section{A MATERNIDADE E 0 ENCARCERAMENTO}

Para um bom desenvolvimento infantil, é fundamental que o papel de mãe seja exercido fornecendo estimulação adequada à criança, promovendo a sua formação de vínculos e socialização. A questão da maternidade entre as presas envolve uma série de conflitos - a separação dos filhos, a situação dos filhos sem a mãe, o parto que algumas vezes é feito na própria prisão, entre outros. Além disso, existem as questões que envolvem a maternidade antes da prisão, já que em muitos casos há um histórico de negligência infantil decorrente do abuso de drogas ou até mesmo de maus tratos infantis (LEE; FANG; LU0, 2013; DALLEY, 2002).

0 encarceramento agrava problemas já existentes. Dados norte-americanos indicam que, nos casos de problemas com a maternidade prévios à prisão, cerca de $40 \%$ das mulheres já perderam a guarda dos filhos pelo menos uma vez (DALLEY, 2002), deteriorando a relação entre mãe e filhos e acarretando dificuldades emocionais, sociais e comportamentais das crianças. Adicionalmente, surgem novos problemas, pois acompanha a mulher presa o estigma de ser uma "má" pessoa e, consequentemente, não exercer seu papel de mãe adequadamente (DODGE; POGREBIN, 2001).

No Brasil, há uma cautela jurídica para a população de mães encarceradas. No estado de São Paulo, a Lei n. 7210/84 (Lei de Execução Penal) garante a transferência da mulher para uma unidade prisional que possua equipe médica e estrutura para o pré e pós-natal assim que a gravidez é descoberta. Após o parto, a presa tem o direito de permanecer em uma unidade prisional para atendimento e acompanhamento do bebê, e, se não houver vagas em unidades prisionais com berçário, é possivel, pela intermediação de um advogado ou defensor público, solicitar ao juiz seis meses de prisão domiciliar. Além disso, o poder público deve proporcionar assistência psicológica à gestante e à mãe nos períodos pré e pós-natal, inclusive como forma de prevenir ou minorar as consequências do estado puerperal (BRASIL, 1990).

Além da influência da prisão sobre a maternidade, existe o sentido inverso - a maternidade pode ser um fator que influenciou a prisão das mulheres. Não apenas a maternidade, mas também a necessidade de prover melhores condições para os filhos em um ambiente de recursos escassos pode levar mulheres a se envolver em atividades ilícitas, como o envolvimento no tráfico de drogas e em estelionato, pela emissão de cheques sem fundos para 0 pagamento de dívidas (FERRARO; MOE, 2003). Em sua coleta de depoimentos em uma delegacia do estado de Minas Gerais, Guedes (2006) descreve que muitas das mulheres alegavam uma relação entre os delitos cometidos e a tentativa de assegurar aos filhos acesso ao conforto e aos bens de consumo divulgados na mídia.

A respeito da situação dos filhos sem a mãe, surge outro problema que requer atenção tais crianças são colocadas muitas vezes em lares adotivos temporários, o que dificulta a criação de vínculo entre as crianças e seus cuidadores e o desenvolvimento adequado delas. 
A existência de vínculo é crítica para o desenvolvimento da criança, principalmente nos dois primeiros anos de vida. Além do problema do vínculo, nesses lares, é comum a ocorrência de abusos e negligência por parte do cuidador temporário, aumentando a probabilidade de um desenvolvimento inadequado, tal como apontado em Johnston (1995).

Sobre a população encarcerada recai um olhar muito crítico da sociedade, e essa sombra acaba incidindo também em seus filhos. Assim que sai da prisão, a mulher enfrenta uma série de dificuldades relacionadas à retomada de seu papel de mãe. Tendo em vista a proteção às crianças, o governo norte-americano estabelece critérios rígidos a respeito da devolução da guarda das crianças às mães uma vez encarceradas - as mulheres têm que demonstrar sua boa condição para ganhar o direito de exercer a maternidade novamente, como frequentar programas de reabilitação para usuários de álcool ou drogas, estar empregada e receber um salário que possibilite o sustento das crianças, possuir residência fixa e adequada para a presença de crianças e não estar envolvida em atividades criminais (DODGE; POGREBIN, 2001).

Dados da Secretaria de Administração Penitenciária do Estado de São Paulo (SAP-SP), que descrevem a média de escolarização das mulheres encarceradas brasileiras, mostram que apenas 1,3\% tem ensino superior completo, e a maioria não chega a completar o ensino fundamental. Sendo assim, muitas mulheres encarceradas não apresentam um alto nível de escolaridade, o que dificulta o seu reingresso no mercado de trabalho. Como consequência, tal população sofre extrema exclusão social e tem oportunidades reduzidas de educação e emprego (ORMENO; STELKO-PEREIRA, 2013).

\section{O CICLO DA VIOLÊNCIA}

A teoria do ciclo intergeracional da violência se baseia na teoria da aprendizagem social (BANDURA, 1977) e pode ser enunciada como a sugestão de que se alguém cresce testemunhando ou sendo vítima de violência conjugal direta ou indiretamente estará predisposto a agir de forma violenta em seus próprios relacionamentos intimos (HARRIS; DERSCH, 2001).

Estudos norte-americanos mostram que as crianças estão presentes em $80 \%$ das vezes em que suas mães são agredidas pelos parceiros e 75\% dos homens que abusam de mulheres presenciaram violência nas familias de origem (HARRIS; DERSCH, 2001), e dados brasileiros corroboram esses achados (BRANCALHONE; FOGO; WILIAMS, 2004; PADOVANI; WILLIAMS, 2011). Ainda segundo os autores mencionados, é comum observar a relação entre adolescentes infratores e pais agressivos, e, além disso, observar a violência entre os pais é mais preditivo para o comportamento de agredir a companheira do que ser a própria vítima de abuso durante a infância. Maldonado e Williams (2005) relacionam comportamentos agressivos apresentados por crianças na escola e exposição à violência doméstica, demonstrando que 
crianças que apresentam comportamentos agressivos na escola estão expostas à violência doméstica mais severa que aquelas que não apresentam tais comportamentos.

Segundo Dalley (2002), as mulheres presas geralmente são oriundas de famílias com histórico de violência. Cerca de $80 \%$ delas sofreram abuso físico durante a infância ou adolescência, e quase 30\% enfrentaram problemas com a drogadição de pelo menos um dos pais. Há ainda relatos de negligência e encarceramento dos pais no histórico de vida dessas mulheres. De acordo ainda com Dalley (2002), devemos tratar os filhos dessas mulheres como uma população em risco de ser a próxima geração de presidiários, por terem sofrido traumas similares aos sofridos por suas mães.

Mauá e Baltieri (2012) realizaram um estudo transversal em uma penitenciária feminina no estado de São Paulo e constataram que ter antecedentes familiares de condenação por crimes prediz consistentemente um início mais precoce de atividades criminais e uma carreira criminal mais longa em mulheres assaltantes. Apesar desses dados, é importante retomar que ter sido vítima/testemunha de violência não é determinante para se tornar agressor, pois há diversos fatores de proteção que influenciam o desenvolvimento de cada indivíduo, podendo protegê-lo e torná-lo resiliente.

\section{FATORES DE RISCO, PROTEÇÃO E RESILIÊNCIA}

Os fatores de risco e proteção são conceitos utilizados para definir variáveis ambientais, cognitivas ou da personalidade que afetam a vida das pessoas ao longo do desenvolvimento, de forma a protegê-las de envolver-se em comportamentos de risco ou influenciá-las a ter tais comportamentos. Fator de risco define fatores ambientais ou biológicos que podem resultar em comportamentos indesejáveis. Fatores ambientais estão relacionados a condições desfavoráveis como pobreza, catástrofes naturais, negligência e eventos estressores no geral. Já fatores pessoais podem ser tanto relacionados à cognição quanto à saúde, como autismo, desnutrição, prematuridade, entre outros. Essas condições tornam o indivíduo vulnerável e podem levar à execução de comportamentos de risco - como uso de álcool e drogas e desordem de conduta (PESCE et al., 2004; DE ANTONI; RODRIGUEZ; KOLLER, 2007).

Quando muitas situações de risco se associam, elas dificultam o cumprimento da agenda desenvolvimental, bem como a aquisição de habilidades e o desempenho de papéis sociais. Por isso, a importância em prever fatores de risco não está tanto relacionada ao prognóstico ruim, mas principalmente em demonstrar a necessidade e de ser capaz de intervir quando for preciso (SAPIENZA; PEDROMÔNICO, 2005).

Fatores de proteção são considerados variáveis independentes que podem ter seus próprios efeitos diretos no comportamento e, além disso, moderar a relação entre fatores de risco e comportamento (GARCIA; WILLIAMS; BRINO, 2009). Podem ser distribuídos em três 
categorias: atributos disposicionais da criança, características da família e fontes de apoio individual ou institucional (MAIA; WILLIAMS, 2005). Tais fatores serão protetivos à medida que favorecerem o desenvolvimento adequado da criança, como autoestima elevada para a primeira categoria, afetividade e ausência de discórdia e negligência para a segunda categoria, e suporte cultural e acesso a atendimentos individuais médicos e/ou psicológicos para a última categoria. Em situações hostis, esses mecanismos podem dar suporte e prevenir o envolvimento com situações de risco. Além disso, podem também ser um fator preditivo da resiliência.

A resiliência refere-se à capacidade da pessoa em lidar com as situações adversas. Junqueira e Deslandes (2003) tratam a resiliência como uma capacidade do sujeito de, em determinados momentos e de acordo com as circunstâncias, lidar com a adversidade, não sucumbindo a ela. 0 constructo da resiliência, de acordo com Grotberg (1997), envolve a capacidade do individuo de enfrentar experiências de adversidade e, além disso, recuperar-se e sair fortalecido ou até mesmo transformado por elas.

Todos esses conceitos, em conjunto, teorizam sobre o desenvolvimento do indivíduo e as influências que recebe ao longo da vida. Essas influências e variáveis podem ser tanto benéficas como maléficas, e, a partir delas, conseguimos entender como as práticas educativas podem afetar o desenvolvimento infantil, sendo um fator de risco ou de proteção.

\section{PRÁTICAS EDUCATIVAS PARENTAIS E O DESENVOLVIMENTO INFANTIL}

A família pode, então, atuar tanto de maneira a favorecer o desenvolvimento adequado das crianças, quanto a favorecer o aparecimento de comportamentos antissociais nelas, atuando como fator de proteção ou de risco ao desenvolvimento infantil (MAIA; WILLIAMS, 2005). A relação entre pais e filhos é influenciada por diversos fatores, como experiências individuais, apoio social, personalidade, temperamento, estresse, aceitação do uso de punições corporais e características da criança, e disfunções nessa relação podem ter efeitos devastadores no desenvolvimento dos filhos (PALUSCl et al., 2008). 0 aprisionamento de um dos pais pode ser o causador desses efeitos devastadores, contudo a maneira de manejar essa relação é de fundamental importância para um bom desenvolvimento.

Segundo Gomide (2003), os pais, entre outras funções, assumem o papel de agente de socialização dos filhos e, para isso, utilizam estratégias e técnicas para orientar seus comportamentos - as chamadas práticas educativas parentais. Essas práticas podem favorecer comportamentos pró ou antissociais, e aquelas que favorecem os primeiros tipos de comportamento são classificadas como práticas educativas positivas (monitoria positiva e comportamento moral) e as que favorecem os segundos tipos de comportamento são classificadas como práticas educativas negativas (abuso físico e psicológico, disciplina relaxada, monitoria negativa, negligência e punição inconsistente). 
Os estilos e as práticas parentais foram assunto de diferentes estudos e classificados primeiramente por Baumrind (1966) em três categorias: permissivo, autoritário e com autoridade. Essas categorias eram chamadas de protótipos parentais e baseavam-se no controle que os pais exerciam sobre os filhos. 0 permissivo correspondia a relações em que os pais não exigiam muitas responsabilidades dos filhos, deixando que eles se autorregulassem; 0 estilo autoritário era composto por pais controladores, e a criança não tinha autonomia; e, por último, o autoritativo era aquele que procurava direcionar a criança para as atividades, contando com o ponto de vista delas. Após essa classificação, muitas outras surgiram de forma aprimorada para conseguir englobar os mais diferentes aspectos que envolvem a relação pais-filhos na educação.

Diversos fatores interferem no desenvolvimento de crianças que são filhos de mães encarceradas. Em especial, eles estão expostos a diversos fatores que prejudicam o seu desenvolvimento. Um desses fatores é o ambiente em que a criança foi inserida após a prisão da mãe, exercendo influência direta em seu desenvolvimento, pois é nele que aparecem os novos fatores de risco ou de proteção. Além disso, o próprio encarceramento materno com a consequente falta de contato com a mãe pode ser prejudicial à criança. Ter a mãe como cuidadora principal e até mesmo como única cuidadora acarreta maiores problemas quando ela sai de cena. Há, entretanto, a necessidade de mais estudos sobre o assunto.

Os filhos de encarcerados compõem uma porcentagem esquecida tanto pelo governo quanto pelos estudiosos da área, o que é refletido pela existência de poucos trabalhos com essa população (MURRAY; FARRINGTON, 2008; ORMENO; MAIA; WILLIAMS, 2013). Estudá-los possibilita agir preventivamente, rompendo o ciclo de violência e um possivel e consequente encarceramento da próxima geração.

\section{OBJETIVO}

0 presente estudo pretende avaliar as práticas educativas mais utilizadas por mães encarceradas no período anterior ao encarceramento e as práticas educativas que elas receberam em suas famílias de origem, na infância.

\section{MÉTODO}

\section{Participantes}

Participaram do estudo 45 mulheres, mães com filhos de até 15 anos de idade, que se encontravam em regime prisional fechado, em penitenciárias, cadeias ou centros de ressocialização do interior do estado de São Paulo. 


\section{Local de coleta de dados}

Os dados foram coletados nos centros prisionais onde as presas se encontravam, em visitas pré-agendadas pela pesquisadora, com auxilio da Defensoria Pública do Município e autorização das direções das instituições.

\section{Considerações éticas}

0 projeto de pesquisa foi submetido ao Comitê de Ética em Pesquisa em Seres Humanos (CEP) da Universidade Federal de São Carlos - Certificado de Apresentação para Apreciação Ética (Caae) n. 0016.0135.000-09 - e também ao Comitê de Ética da SAP-SP - Parecer Consubstanciado do CEP-SAP: 042/2011. A coleta de dados só teve início após essas aprovações.

As participantes assinaram o Termo de Consentimento Livre e Esclarecido (TCLE) para garantir os cuidados éticos necessários na pesquisa, como sigilo e confidencialidade das informações fornecidas. Além disso, foram devidamente informadas de que não haveria qualquer postura punitiva para aquelas que não desejassem participar do estudo.

\section{Instrumento}

Aplicou-se o Inventário de Estilos Parentais (IEP) desenvolvido por Gomide (2007) para avaliar estilos parentais. Para a presente pesquisa, utilizou-se a versão do inventário aplicável em pais, a qual é composta por 42 questões que avaliam sete práticas educativas: duas positivas (monitoria positiva e comportamento moral) e cinco negativas (abuso físico e psicológico, disciplina relaxada, monitoria negativa, negligência e punição inconsistente). São apresentadas seis questões para cada tipo de prática, e, para cada questão, há três tipos de resposta: nunca, às vezese sempre. Sua pontuação gera escores de cada uma das práticas e, também, o índice de estilo parental geral (SAMPAIO; GOMIDE, 2007).

\section{Procedimento}

Após aprovado o projeto pelos comitês de ética, a coleta foi feita em três instituições diferentes: uma cadeia, uma penitenciária e um centro de ressocialização.

0 procedimento geral consistiu em selecionar aleatoriamente as mulheres que aceitassem participar da pesquisa, com critério de ter filhos com idade até 15 anos. Após assinatura do TCLE, aplicou-se o IEP em duas versões: a primeira referente à conduta da encarcerada com seu o próprio filho, e a segunda referente à conduta de mãe em sua familia de origem (tais informações consistiam em dados retrospectivos, pois faziam alusão à infância da encarcerada). A aplicação do IEP durou em torno de 20 minutos para ambas as versões. A coleta de 
dados foi realizada no local em que a mulher se encontrava encarcerada, em sala cedida pela coordenadoria do sistema prisional.

\section{Delineamento experimental}

Trata-se de uma pesquisa de levantamento (survey) com amostragem por conveniência no que diz respeito à escolha das instituições nas quais foram realizadas as coletas (COZBY, 2003).

\section{Análise dos dados}

Os IEPs foram pontuados conforme as orientações do respectivo manual, sendo a resposta nunca equivalente a zero ponto, às vezes pontuada com um ponto e sempre equivalente a dois pontos. Para obtenção do escore relativo a cada prática, é realizada a somatória por prática, de acordo com as questões respectivas, a saber: questões de monitoria positiva (prática A) - questões 1, 8, 15, 22, 29 e 36; de comportamento moral (prática B) - questões 2, 9, 16, 23, 30 e 37; de punição inconsistente (prática C) - questões 3, 10, 17, 24, 31 e 38; de negligência (prática D) - questões 4, 11, 18, 25, 32 e 39; de disciplina relaxada (prática E) questões 5, 12, 19, 26, 33 e 40; de monitoria negativa (prática F) - questões 6, 13, 20, 27,34 e 41; e, por fim, de abuso físico (prática G) - questões 7, 14, 21, 28, 35 e 42.

Para obtenção do escore total, o índice de estilo parental, deve-se subtrair a soma das práticas negativas das positivas, o que pode ser representado pela seguinte fórmula:

$$
I E P=(A+B)-(C+D+E+F+G)
$$

Os dados obtidos, tanto referentes às práticas individuais como para o escore geral, foram analisados em tabelas que indicarão as práticas educativas apresentadas com maior frequência pela população analisada.

\section{RESULTADOS E DISCUSSÃO}

0 presente estudo teve como objetivo principal avaliar as práticas parentais mais utilizadas por mães encarceradas no período anterior ao encarceramento e as práticas educativas que elas receberam em sua infância na familia de origem.

Antes da análise dos resultados, fez-se uma análise estatística referente às populações em cada instituição para verificar se havia algum tipo de discrepância em relação à caracterização dessas mulheres pelo fato de os dados terem sido coletados em três instituições 
distintas - cadeia, penitenciária e centro de ressocialização, já que na cadeia ficam os presos provisórios, que ainda não foram julgados e condenados; após julgamento, os presos sentenciados vão para a penitenciária; e o centro de ressocialização consiste em uma iniciativa do governo do estado de São Paulo no sentido de favorecer o retorno de indivíduos em situação prisional ao convívio em sociedade. A partir dessa análise, ficou evidente não haver diferenças significativas $\left(p=0,073 ; p<0,05^{*}\right)$ quanto ao local onde as presas se encontravam, e, por esse motivo, os dados foram analisados como um todo.

As participantes apresentavam idade entre 18 e 43 anos (média =28; DP =3,53); e o grau de escolaridade variava de ensino fundamental incompleto (EFM) a ensino médio completo (EMC); e 33\% tinham ensino fundamental incompleto; 25\%, ensino fundamental completo (EFC); 31\%, ensino médio incompleto (EMI); e 11\%, EMC. A Tabela 1 apresenta a comparação dos testes com os escores brutos de mães e filhos.

Tabela 1 Comparação pelo teste de Mann-Whitney entre a média dos escores brutos do IEP das encarceradas e de suas mães

\begin{tabular}{lcccc} 
& \multicolumn{3}{c}{ Médias } & \\
\cline { 2 - 5 } \multicolumn{1}{c}{ Prática parental } & Encarcerada & Mãe da encarcerada & Teste & $p$ \\
\hline Monitoria positiva & 10.578 & 8.111 & 669 & .005 \\
\hline Comportamento moral & 9.933 & 8.667 & 863 & .23 \\
\hline Punição inconsistente & 3.644 & 4.133 & 891.5 & .331 \\
\hline Negligência & 3.156 & 4.667 & 753.5 & .036 \\
\hline Disciplina relaxada & 3.867 & 3.422 & 911 & .417 \\
\hline Monitoria negativa & 6.644 & 6.311 & 911.5 & .417 \\
\hline Abuso físico & 2.4 & 3.8 & 793 & .077 \\
\hline
\end{tabular}

Fonte: Elaborada pelos autores.

Em média, com base na Tabela 1, a prática educativa mais utilizada pelas mães encarceradas antes do encarceramento, com seu filho, foi a monitoria negativa. A monitoria negativa se caracteriza pelo excesso de fiscalização da vida dos filhos e pela grande quantidade de instruções repetitivas, que não são seguidas por eles. Essa prática educativa gera ambientes familiares estressados e sem diálogo, uma vez que os filhos podem fazer uso de comportamentos agressivos para proteger sua privacidade dos pais (GOMIDE, 2003). Sendo assim, tal comportamento pode prejudicar a cumplicidade entre pais e filhos, tornando-se punitivo.

Os escores das avós das crianças, mãe das mulheres encarceradas, tiveram como média predominante também a monitoria negativa e adicionalmente a negligência. Gomide (2007) 
descreve as mães negligentes que não aceitam suas responsabilidades e são limitadas em competência. Nessas condições, as crianças se tornam muito passivas e podem sofrer com déficits comportamentais. Além disso, a monitoria negativa consiste em uma prática prejudicial, que pode dilapidar o relacionamento dentro da familia.

Ainda na Tabela 1, com a aplicação do teste de Mann-Whitney, foi possível encontrar diferenças significativas para monitoria positiva $\left(p=0,005 ; p<0,05^{*}\right)$ e negligência $(p=0,036$; $p<0,05^{*}$ ). Esse dado denota que, para essas duas práticas parentais, há diferença de uma geração para a outra, isto é, a mulher encarcerada teve um significativo aumento da média em monitoria positiva em comparação à avó, e uma significativa diminuição da média de negligência se comparada também à avó, significando uma melhora nessas duas práticas.

Quando se analisam os dados em pares de mãe e filha na mesma tabela, pode-se perceber que houve intergeracionalidade do estilo parental em 56\% dos casos. Esse dado confirma a hipótese inicial de que os estilos parentais são transmitidos de geração para geração, na maioria dos casos. Nessa situação, a transmissão ocorreu em casos de estilo parental de risco e abaixo da média em sua maioria, indicando a necessidade de intervenções com essas mães para que esse padrão não prossiga nas gerações seguintes.

Weber et al. (2006) fazem uma ponte entre os estilos parentais e sua transmissão através das gerações. A pesquisa mediu escalas como relacionamento afetivo, envolvimento, regras, reforçamento, comunicação positiva dos pais e dos filhos, comunicação negativa, entre outras, em 21 mulheres de sete familias distintas de classe média, respeitando a linearidade trigeracional (avó/filha/neta). Os resultados são comparados entre a primeira e segunda, segunda e terceira, e primeira e segunda gerações, e em aproximadamente $91 \%$ das variáveis houve intergeracionalidade.

Apesar de se saber que houve intergeracionalidade dos estilos parentais, a porcentagem de mulheres que não manteve o mesmo estilo foi expressiva (44\%). No Gráfico 1, temos a comparação dos escores da avó e da mãe. Nota-se que, em todos os tipos de estilo parental, a avó (primeira geração) tem um escore do estilo parental menor do que o da encarcerada (segunda geração), isso é corroborado pelo teste-t $\left(p=0,010, p<0,05^{*}\right)$ que comprova que houve diferenças significativas entre mãe e filha, indicando que a filha tem um IEP médio maior do que o da avó, isto é, um estilo parental melhor.

Em seu estudo, Weber et al. (2006) notaram que, nos casos em que não houve intergeracionalidade, ocorreu uma melhora no estilo parental de acordo com o avanço das gerações. De acordo com esses autores, as mudanças socioculturais pelas quais a sociedade passa ao longo dos anos e maior divulgação de informações científicas a respeito de educação de filhos podem ajudar na melhora do estilo parental. 
Gráfico 1 Comparação dos escores do estilo parental da mulher encarcerada e da mãe da encarcerada

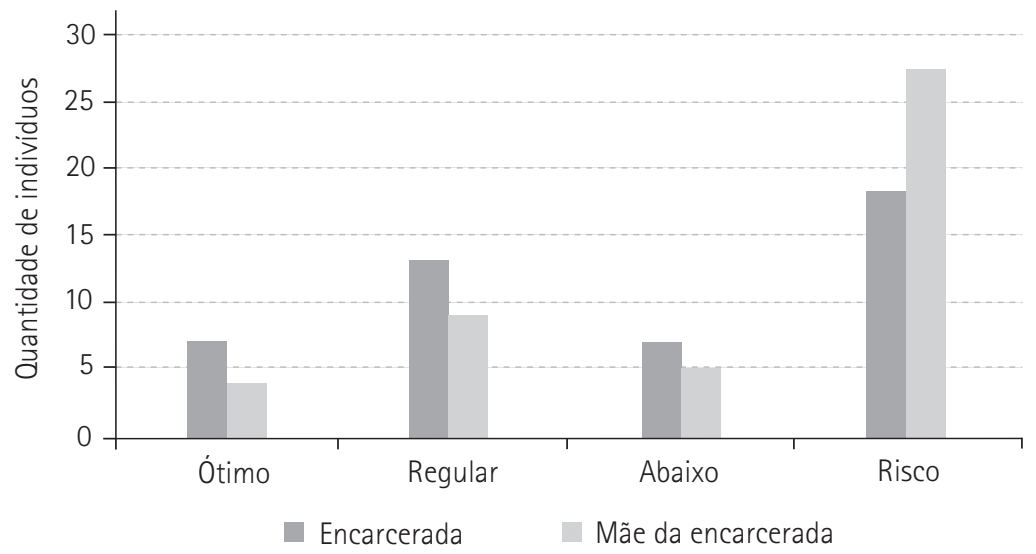

Fonte: Elaborado pelos autores.

Figura 1 Média dos escores das duas gerações

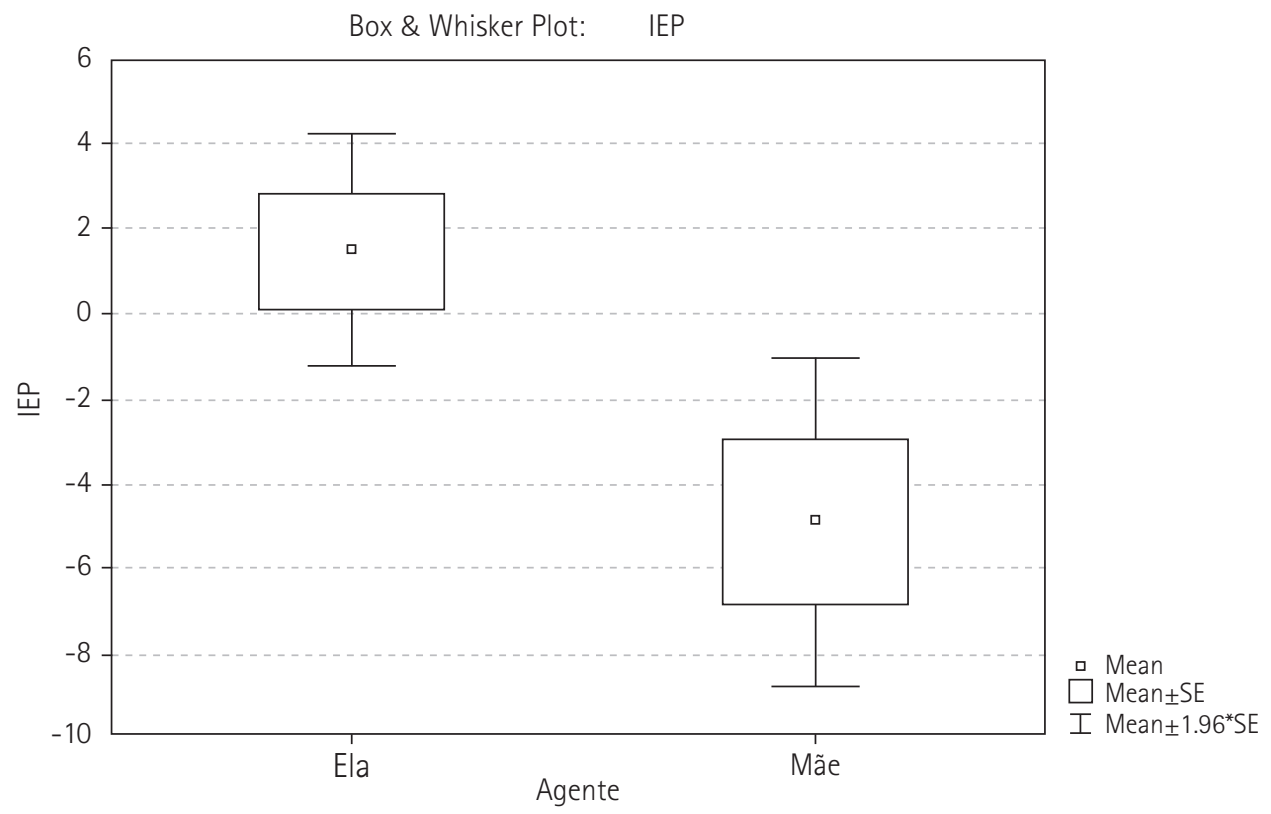

Fonte: Elaborada pelos autores.

A Figura 1 representa a distribuição da média dos escores do IEP das mulheres encarceradas e de suas mães. 0 quadrado central representa a média da maioria das mulheres e seu escore no IEP. É possivel notar que, em média, a mulher encarcerada tem o escore do IEP 
entre zero e dois, indicando um estilo parental abaixo da média, já a mãe da mulher encarcerada se encontra entre seis e quatro, indicando um estilo parental de risco.

Sendo assim, apesar de as mulheres encarceradas terem escores totais mais altos no IEP, em média, o valor máximo alcançado por elas foi um escore regular abaixo da média, e suas mães alcançaram um escore médio negativo, o que significa um estilo parental de risco. Mesmo havendo uma melhora no estilo parental através das gerações, essa melhora ainda não é suficiente, pois as práticas negativas estão competindo com as práticas positivas.

0 estudo sobre os estilos parentais característicos de famílias provenientes de contextos de alta vulnerabilidade social de Rinhel-Silva, Constantino e Rondini (2012) permite refletir sobre a importância das relações entre pais e mães e seus filhos, e o desenvolvimento de programas sociais que envolvam a orientação de pais, no sentido de criar novas práticas que visem fortalecer os vínculos parentais de famílias sujeitas a tal contexto. Dessa maneira, pode-se pensar também em intervenções com as famílias das mães encarceradas, pois, como mencionado no estudo de Rinhel-Silva, Constantino e Rondini (2012), a mãe vem assumindo, atualmente, além do papel de dar afeto, também o de impor limites e regras que antes eram designados em sua maioria à figura paterna, e, como as mães encarceradas já não estão presentes em uma parte do desenvolvimento dos filhos, é necessário que haja outras referências com as quais a criança possa se identificar. A Tabela 2 apresenta a escolaridade das mulheres encarceradas.

Tabela 2 Distribuição da classificação dos escores do IEP conforme escolaridade das encarceradas

\begin{tabular}{|c|c|c|c|c|}
\hline \multirow[b]{3}{*}{ Escolaridade } & \multicolumn{4}{|c|}{ IEP } \\
\hline & \multirow[b]{2}{*}{ Ótimo } & \multicolumn{2}{|c|}{ Regular } & \multirow[b]{2}{*}{ Risco } \\
\hline & & Acima da média & Abaixo da média & \\
\hline \multicolumn{5}{|l|}{ Ensino fundamental } \\
\hline Incompleto & 2 & 3 & 1 & 9 \\
\hline Completo & 2 & 3 & 2 & 4 \\
\hline \multicolumn{5}{|l|}{ Ensino médio } \\
\hline Incompleto & 0 & 6 & 4 & 4 \\
\hline Completo & 1 & 1 & 1 & 2 \\
\hline
\end{tabular}

Fonte: Elaborada pelos autores.

Percebe-se que nove das 45 mulheres tinham o ensino fundamental incompleto e apresentam maior índice de estilo parental de risco. 0 estudo de Gomide (2009) procurou avaliar a percepção dos filhos sobre suas mães, sendo estes divididos entre filhos de engenheiras, 
médicas, advogadas e psicólogas. Surpreendentemente, mães com formação de nível superior e ativas no mercado de trabalho tiveram um baixo desempenho de práticas educativas parentais quando avaliadas por seus filhos. Os resultados de Gomide (2009) mostraram que as mães, independentemente da profissão, utilizam pobremente as práticas educativas positivas (monitoria positiva e comportamento moral) e recorrem, com muita frequência, às práticas negativas (abuso físico e supervisão estressante) para tentar obter controle sobre seus filhos.

Sendo assim, a correlação que há no estigma das mães encarceradas consideradas "más" (DODGE; POGREBIN, 2001) deve ser repensado, pois os conhecimentos, a formação profissional e a maior exposição a informações, embora tenham ocorrido em níveis diferentes para cada profissão no estudo de Gomide (2009), aparentemente não foram suficientes para melhorar as práticas educativas parentais e inibir o estresse causado pela dupla jornada de trabalho e pela ausência de rede de apoio.

\section{CONSIDERAÇÕES FINAIS}

Este trabalho teve como objetivo principal analisar quais práticas parentais foram mais utilizadas por mães encarceradas antes do encarceramento e quais práticas parentais elas receberam de sua familia de origem. Obteve-se como resultado que as práticas parentais mais utilizadas foram a monitoria negativa para as mulheres encarceradas e monitoria negativa e negligência para as mães das mulheres encarceradas. Além disso, foi possível constatar que houve intergeracionalidade das práticas parentais na maioria dos casos.

Trabalhos que estudem a população carcerária no Brasil vêm aumentando, e é possivel ver um avanço na literatura atual que envolve não apenas os encarcerados, mas também a família envolvida. No entanto, o que falta é uma intervenção sistemática que lide com tal população, pois, como os estudos são recentes, ainda não há dados consolidados. Nos Estados Unidos, os trabalhos com encarcerados são diversos e antigos, podendo-se encontrar diferentes modelos de intervenção. Com foco na intervenção com filhos que têm pais encarcerados, o livro Empowering children of incarcerated parents (Empoderando crianças de pais encarcerados) de Burgess, Caselman e Carsey (2009) pode ser usado como referência para a população norte-americana. Nessa obra, expõem-se diferentes formas de manejar as condições em que a criança está exposta, e, com base em estudos, as autoras dão orientações aos cuidadores sobre a melhor forma de lidar com a situação, deixando claro que não se deve mentir e que a verdade deve ser sempre exposta de um jeito que a criança possa entender o que está se passando.

Para a população brasileira, é necessária a criação de uma intervenção específica para a realidade em nosso país, pois podemos ver que nossa população carcerária é muito distinta 
da encontrada no exterior. As entrevistas realizadas com as encarceradas revelaram necessidades muito maiores, que vão além do próprio encarceramento. A situação socioeconômica, a questão da guarda dos filhos, a violência intrafamiliar, entre outros fatores, foram assuntos recorrentes nas entrevistas. Deve-se pensar, então, em intervenções multidisciplinares, que não tratem apenas o problema do encarceramento, mas também de toda a situação de risco aqui descrita em que tal população se encontra.

É fundamental a criação de políticas públicas, uma vez que são muitos os fatores de risco envolvidos, e dificilmente uma intervenção pontual pode vir a solucionar o problema, pois muitas vezes a prisão se deu pelo fato de a pessoa viver em um ambiente hostil. Outro ponto importante é que as intervenções devem servir para prevenir, criando mais fatores de proteção do que os fatores de risco existentes na vida dessas pessoas. Sugere-se a criação de redes de apoio tanto para adultos como para as crianças, que vise ao entendimento da dinâmica familiar e da própria comunidade e consiga se inserir nos pontos falhos que levam as pessoas a ter comportamentos de risco. Essas redes de apoio e proteção deveriam estar localizadas em vários lugares da comunidade, em que a pessoa está inserida, nas escolas, no trabalho, a fim de proporcionar mais oportunidades a esses sujeitos de modo que não se envolvam em comportamentos de risco.

\section{Limitações do estudo}

Uma das primeiras observações a serem feitas sobre esta pesquisa foi a demora em coletar os dados. A lentidão nas respostas e a burocracia impediram a coleta com um número maior de mulheres. Além disso, apesar de o número de encarceradas em cada localidade ser alto, a quantidade de mulheres que se dispuseram a participar foi baixa. Hipóteses podem ser levantadas a respeito desse dado, como o fato de o tema abordado ser delicado e referente à vida pessoal, o que pode ter levado muitas delas a prever desconforto e se ausentar. Conforme o relato dos agentes penitenciários, muitas mulheres não se interessam em participar de nenhuma pesquisa. Sendo assim, pode-se dizer que não houve pouca adesão ao estudo aqui realizado, mas, sim, a estudos em geral que ocorrem dentro dos centros prisionais.

Durante as entrevistas, muitas das mulheres se emocionaram ao fazerem comentários sobre o relacionamento com seus filhos ou respectivas mães, e mesmo que a entrevista tenha se dado em um contexto psicológico, isto é, ocorreu de maneira a minimizar os possíveis desconfortos, ainda assim o assunto pareceu causar algum tipo de angústia nas entrevistadas.

Sobre a questão de utilizar entrevista como forma de coleta de dados, pode-se inferir que os resultados não sejam exatamente fiéis descrições do comportamento real das mães e avós. Uma hipótese a ser levantada é de que muitas das mulheres encarceradas deram respostas socialmente aceitas quando se tratava da maneira como elas educaram seus filhos, e, por esse motivo, não foi encontrada uma maior transmissão intergeracional. Especificamente, os 
resultados apontam que, se não houver uma intervenção e quebra dos padrões da intergeracionalidade, a violência poderá crescer em altas proporções. Acredita-se então que este estudo venha na direção de contribuir para a caracterização de tal público, para que este possa ser alvo de maiores estudos futuros.

\title{
Evaluation of parental practices in imprisoned mothers
}

\begin{abstract}
Abstract: Little is studied about the Brazilian prison population, much less about their relatives. This population, growing every day, become invisible in the eyes of society because they are stigmatized and labeled as "bad people." However, the influence of it is more striking than it appears. After all, not only the prison population has a substantial impact on the country's economy, but also their families, especially children, are at serious risk of becoming the next generation of prisoners, thus building a cycle of violence that is difficult to break. The present study aimed to evaluate parental practices used by mothers who are incarcerated. To do this, the Inventory of Parenting Styles (IPS) was applied to imprisoned women to obtain information about the intergenerational transmission of parental styles. Two generations were analyzed, firstly understanding which parental practices were used with the woman jailed as a child, and then, what educational methods this woman used with her child before the incarceration, thus helping to understand the intergenerationality of violence. The results showed that the educational practice most used by the incarcerated woman and her mother was harmful, and intergenerational transmission of such practice could be suggested.
\end{abstract}

Keywords: Parental styles. Incarcerated women. Risk factors. Intergenerationality. Evaluation.

\section{REFERÊNCIAS}

BANDURA, A. Self-efficacy: toward a unifying theory of behaviorial change. Psychological Review, v. 84, n. 2, p. 191-215, 1977. doi: 10.1037/0033-295X.84.2.191

BAUMRIND, D. Effects of authoritative parental control on child behavior. Child Development, v. 37, n. 4, p. 887-907, 1966. doi: 10.2307/1126611

BURGESS, S.; CASELMAN, T.; CARSEY, J. Empowering children of incarcerated parents. Chapin, SC: YouLight, 2009.

BRANCALHONE, P. G.; FOGO, J. C.; WILLIAMS, L. C. A. Crianças expostas a violência conjugal: avaliação do desempenho acadêmico. Psicologia: Teoria e Pesquisa, v. 20, n. 2, p. 113-117, 2004. doi: http://dx.doi.org/10.1590/S0102-37722004000200003

BRASIL. Lei n. 8.069, de 13 de julho de 1990. Dispõe sobre o Estatuto da Criança e do Adolescente e dá outras providências. Brasilia, 1990. Disponivel em: <http://www.planalto.gov.br/ ccivil_03/leis/L8069.htm>. Acesso em: 21 jan. 2013. 
CANAZARO, D.; ARGIMON, I. I. de L. Caracteristicas, sintomas depressivos e fatores associados em mulheres encarceradas no estado do Rio Grande do Sul. Caderno de Saúde Pública, v. 26, n. 7, p. 1323-1333, 2010.

COSTA, R. W. da; VIEIRA, R.; PESSINI, M. A. A maternidade da mulher encarcerada. Akrópolis, V. 19, n. 3, p. 141-153, jul./set. 2011.

COZBY, P. C. Métodos de pesquisa em ciência do comportamento. São Paulo: Atlas, 2003.

DE ANTONI, C.; BARONE, L. R; KOLLER, S. Indicadores de risco e de proteção em famílias fisicamente abusivas. Psicologia: Teoria e Pesquisa, v. 23, n. 2, p. 125-132, 2007.

DALLEY, L. P. Policy implications relating to inmate mothers and their children: will the past be prologue? The Prison Journal,v.82, n. 2, p.234-268,2002.doi:10.1177/003288550208200205

DODGE, M.; POGREBIN, M. R. (2001). Collateral costs of imprisonment for women: complications of reintegration. The Prison Journal, v. 81, n. 1, p. 42-54, 2001. doi: 10.1177/0032885501 081001004

FERRARO, K. J.; MOE, A. M. Mothering, crime, and incarceration. Journal of Contemporary Ethnography, v. 32, n. 1, p. 9-40, 2003. doi: 10.1177/0891241602238937

GARCIA, S. C.; WILLIAMS, L. C. A.; BRINO, R. F. Risco e resiliência em escolares: um estudo com múltiplos instrumentos. Psicologia da Educação, v. 28, p. 23-49, 2009. Disponível em: <http:// pepsic.bvsalud.org/pdf/psie/n28/v28a03.pdf>. Acesso em: 31 jan. 2014.

GOMIDE, P. I. C. Inventário de Estilos Parentais (IEP) - Gomide (2006) percurso de padronização e normatização. Psicologia Argumento, v. 25, n. 48, p. 15-26, 2007. Disponivel em: <https:// periodicos.pucpr.br/index.php/psicologiaargumento/article/view/19675/19007>. Acesso em: 5 fev. 2014.

GOMIDE, P. I. C. Estilos parentais e comportamento anti-social. In: DEL PRETTE, A.; DEL PRETTE, Z. (Orgs.). Habilidades sociais, desenvolvimento e aprendizagem: questões conceituais, avaliação e intervenção. Campinas: Alínea, 2003. p. 22-60.

GOMIDE, P. I. C. A influência da profissão no estilo parental materno percebido pelos filhos. Estudos de Psicologia, v. 26, n. 1, p. 25-34, 2009. doi: 10.1590/S0103-166X2009000100003

GROTBERG, E. H. The international resilience Project. In: ROTH, R. (Ed.). Proceedings of the 55th Annual Convention of the International Council of Psychologists. 1997. Disponivel em: <http://resilnet.uiuc.edu/library/grotb98a.html>. Acesso em: 31 jan. 2013.

GUEDES, M. A. Intervenções psicossociais no sistema carcerário feminino. Psicologia, Ciência e Profissão, v. 26, n. 4, p. 558-569, 2006. doi: 10.1590/S1414-98932006000400004

HARRIS, S. M.; DERSCH, C. A. "I'm just not like that": investigating the intergenerational cycle of violence. The Family Journal, v. 9, n. 3, p. 250-258, 2001. doi: 10.1177/1066480701093003 
JOHNSTON, D. Jailed mother. In: JOHNSTON, D. Children of incarcerated parents. New York: Lexington Books, 1995. p. 22-35.

JUNQUEIRA, M. F. P. S.; DESLANDES, S. F. Resiliência e maus-tratos à criança. Caderno de Saúde Pública, v. 19, n. 1, p. 227-235, 2003. doi: 10.1590/S0102-311X2003000100025

LAUGHLIN, J. S. et al. Incarcerated mothers and child visitation: a law, social science, and policy perspective. Criminal Justice Policy Review, v. 19, n. 2, p. 215-238, 2008. doi: 10.1177/08 87403407309039

LEE, R. D.; FANG, X.; LUO, F. The impact of parental incarceration on the physical and mental health of young adults. Pediatrics Official Journal of the American Academy of Pediatrics, v. 131, n. 4, p. $1188-1195$, 2013. doi:10.1542/peds.2012-0627

MAIA, J. M. D.; WILLIAMS, L. C. A. Fatores de risco e fatores de proteção ao desenvolvimento infantil: uma revisão da área. Temas em Psicologia, v. 13, n. 2, p. 91-103, 2005. Disponível em: <http://pepsic.bvsalud.org/pdf/tp/v13n2/v13n2a02.pdf>. Acesso em: 05 fev. 2014.

MALDONADO, D. P. A.; WILLIAMS, L. C. A. 0 comportamento agressivo de crianças do sexo masculino na escola e sua relação com a violência doméstica. Psicologia em Estudo, v. 10, n. 3, p. 353-362, 2005. doi: 10.1590/S1413-73722005000300003

MAUÁ, F. H. N.; BALTIERI, D. A. Criminal career-related factors among female robbers in the state of São Paulo, Brazil, and a presumed "revolving door" situation. Revista Brasileira de Psiquiatria, v. 34, n. 2,1p. 76-184, 2011. doi: 10.1590/S1516-44462012000200010

MURRAY, J.; JANSON, C.; FARRINGTON, D. P. Crime in adult offspring of prisoners: a crossnational comparison of two longitudinal samples. Criminal Justice and Behavior, v. 34, n. 1, p. 133-149, 2007. doi: 10.1177/0093854806289549

ORMENO G. I. R. Violência contra mulher e a mulher encarcerada no sistema judiciário. Revista da Defensoria Pública do Estado de São Paulo, v. 5, p. 23 -31, 2012.

ORMENO, G. I. R.; MAIA, J.; WILLIAMS, L. C. A. Crianças com pais ou mães encarcerados: uma revisão da literatura. Journal of Child and Adolescent Psychology, v. 4, p. 141-161, 2013.

ORMENO, G. I. R.; STELKO-PEREIRA, A. C. Mulheres encarceradas: nível de escolaridade e motivos para terem evadido da escola. Revista Faz Ciência, v. 15, n. 22, p. 65-77, 2013.

PADOVANI, R. C.; WILLIAMS, L. C. A. Estilo parental de origem e ansiedade em homens com histórico de agressão à parceira. Estudos de Psicologia, v. 16, n. 3, p. 263-269, 2011. doi: 10.1590/ S1413-294X2011000300008

PALUSCI, V. J. et al. Changes in parenting attitudes and knowledge among inmates and other at-risk populations after a family nurturing program. Children and Youth Services Review, v. 30, n. 1, p. 79-89, 2008. doi: 10.1016/j.childyouth.2007.06.006 
PESCE, R. P. et al. Risco e proteção: em busca de um equilibrio promotor de resiliência. Psicologia: Teoria e Pesquisa, v. 20, n. 2, p. 135-143, 2004. doi: 10.1590/S0102-37722004000 200006

RINHEL-SILVA, C. M.; CONSTANTINO, E. P.; RONDINI, C. A. Familia, adolescência e estilos parentais. Estudos de Psicologia, v. 29, n. 2, p. 221-230, 2012. doi: 10.1590/S0103-166X201200 0200008

SAPIENZA, G.; PEDROMÔNICO, M. R. M. Risco, proteção e resiliência no desenvolvimento da criança e do adolescente. Psicologia em Estudo, v. 10, n. 2, p. 209-216, 2005. doi: 10.1590/S14 13-73722005000200007

SCHERER Z. A. P.; SCHERER. E. A. Concepções e vivências de mulheres encarceradas sobre a violência. Cogitare Enfermagem, v. 14, n. 3, p. 435-440, 2009. Disponivel em: <http://ojs.c3sl. ufpr.br/ojs/index.php/cogitare/article/viewFile/16160/10680>. Acesso em: 31 jan. 2013.

SOARES, B. M.; ILGENFRITZ, I. Prisioneiras: vida e violência atrás das grades. Rio de Janeiro: Garamond, 2002.

STELLA, C. Filhos de mulheres presas: o papel materno na socialização do indivíduo. Estudos e Pesquisas em Psicologia, v. 9, n. 2, p. 292-306, 2009. Disponivel em: <http://www.revispsi. uerj.br/v9n2/artigos/pdf/v9n2a03.pdf>. Acesso em: 22 jun. 2014.

WEBER, L. N. D. et al. Continuidade dos estilos parentais através das gerações - transmissão intergeracional de estilos parentais. Paidéia, v. 16, n. 35, p. 407-414, 2006. doi: 10.1590/S0 $103-863 \times 2006000300011$ 